\title{
Intervention Programs for Developing Play Skills in Children With Autistic Spectrum Disorder to Foster Interaction
}

\author{
Faris Algahtani ${ }^{1}$ \\ ${ }^{1}$ Department of Special Education, Faculty of Education, University of Jeddah, Saudi Arabia \\ Correspondence: Faris Algahtani, Department of Special Education, Faculty of Education, University of Jeddah, \\ Saudi Arabia. E-mail: fhalqahtani@uj.edu.sa
}

Received: February 5, 2018 Accepted: March 5, 2018 Online Published: March 20, 2018

doi:10.5539/gjhs.v10n5p26

URL: https://doi.org/10.5539/gjhs.v10n5p26

\begin{abstract}
Autistic spectrum disorder has gained attention in terms of developing therapies and support to enhance the developmental and social attributes of children. The aim of this study is to assess the favourable influence of play therapies among autistic children. An observational analysis has been conducted in a local rehabilitation centre. A class of 250 autistic children, aged between 4 to 5 years, was evaluated. Pre and post analysis for common indications of autism were made with regard to the play therapy. The symptoms, concerning behavioural aspects, were recorded on a simple checklist. The study did not provide any concrete relevancy of being effective for play therapy among the autistic children. The study showed that interventions based on play skills are recognized as imperative approach to develop social associations among children. The developmental approaches of autistic children differ from normal children, as they require different facilities and special attention.
\end{abstract}

Keywords: autistic children, autistic spectrum disorder, intervention, play therapy

\section{Introduction}

Autism Spectrum Disorders (ASD) denote a group of neurodevelopmental disorders that are characterized by qualitative disorders regarding social and communicative interactions and may include repetitive and restricted behaviours. 'ASD' is an umbrella term for autism, Asperger's syndrome, and pervasive developmental disorders that are otherwise unspecified (Landa, 2008). The spectrum of autistic disorders (or autistic spectrum disorder, ASD), denotes a collection of common neurodevelopmental disorders that occur roughly in 110 children per every 10000 children in US (Kogan et al., 2009). It has been discussed in studies that autism sees a four times greater occurrence in boys rather than girls; and thus, it has been implied that being male contributes greatly to the development of ASD (Lord, 2010). It has been suggested by studies that other factors; such as, the advanced age of parents likely serve as contributors to ASD (Grether et al., 2009). Studies detailing the developmental implications of autism stated that infants and toddlers suffering from this disorder may experience excessive brain growth during the initial years of life. This time period strongly coincides with the manifestation of autism symptoms. Following the years of brain overgrowth, it is seen that the brain growth greatly decreases at an unusual rate. This excessive overgrowth was greatly seen in the frontal brain lobes, that grow and develop later and longer than the other brain regions (Courchesne \& Pierce, 2005).

ASD diagnoses are made by adequately describing and observing the behavior of individuals that demonstrate symptoms of ASD (Lord, 2010). This is because a suitable biological test or ASD marker has not yet been developed for suitably diagnosing this neurodevelopmental disorder (Abrahams \& Geschwind, 2008). According to the American Psychiatric Association (1994), ASD is diagnosed on the basis of behavioral aspects that are unusual and that fall within three spheres, namely reciprocal social interaction, communication and restricted, repetitive interests and behaviors. Social interactive disorders are distinguished through poor social-emotional interactions, inability with regard to sharing enjoyments and problematic maintenance of relationships with peers. Disorders with regard to communication are inclusive of speech acquisition inability and complexities with regard to conversing with individuals. Furthermore, restrictive and repetitive behaviors are comprised of atypical preoccupations and confined interests, compulsive behaviors, repetitive finger, and repetitive hand motions. Although, most children with ASD demonstrated social and communicative impairments, they may not necessarily possess repetitive and restrictive behaviors (RRBs). Studies have therefore questioned the extent to which such RRBs inform the ASD diagnosis (Lord, 2010). 
It has been corroborated that young children with Autistic Spectrum Disorder (ASD) often express inability to communicate (Kasari \& Chang, 2014; Flippin \& Watson, 2011). Similarly, majority of children with ASD have been identified with the incapability to be motivated or enjoy interactions. The indications of the condition have gained special interest to identify the related factors and develop efficient management approaches (Chandler, et al, 2013). Autistic spectrum disorder accounts for various characteristics, including; impulsiveness, repetitive behaviours, and compulsive tendencies. Autistic children often spent less time in playing as compared to their normally developing peers. Observations from educational settings have revealed that an autistic child prefers to have only one particular child as his/her companion. Autistic children rarely approach other people for their company, even in the absence of that one liked child (Wong, et al., 2007). Eventually, these children spend their time more alone and avoid group activities (Kasari \& Chang, 2014). They mostly express an inherent lack of flexible motivation, understanding of social experience, and lingual approach that eventually restricts their ability to develop speaking skills (Kasari et al., 2006).

In order to treat ASD, a variety of interventional approaches have been designed to assist autistic children and aid them to develop necessary capabilities, since the acquisition of social interaction skills does not occur naturally in these children (Kasari, et al., 2006). It is to be noted that the treatment methodologies may be medical or otherwise. Studies discussing interventions currently utilized detailed the efficacy of speech therapy (Goldstein, 2002). Additional studies have discussed the prevalence of gluten-free and casein-free diet, sensory integration, and speech therapy as treatment interventions that were highly recommended by medical practitioners (Miller et al., 2012).

There is a need for more effective therapeutic techniques with regard to ASD. The increased rate of ASD diagnosis has pointed towards the need for wider implementation of effective interventions to mitigate the impacts of autism on social skills and speech development (Howlin, 2010). The sustaining interventional programs are encouraged in the educational settings to resolve the interaction between the children, their peers, teacher, and parents to deal with the social reluctance among autistic children.

With regard to intervention methodologies, play therapy is a treatment intervention that has been discussed in various studies (Bratton et al., 2005). Such studies discuss the usefulness of play therapy in the treatment of children's behavioral and emotional problems due to its responsiveness to their unusual needs and requirements. It was stated that a majority of children below the age of 11 do not have a complete ability to process abstract thought, which is integral to verbal expression and comprehension of complex thoughts and feelings (Piaget, 1962). Children with ASD characteristically experience cognitive and behavioral complications during their life, particularly in the developing age (Lillard et al., 2013; Jana Mertz, 2013). Play skills are considered imperative due to their ability to develop a healthy learning environment, during preschool years. Classroom participation is a necessary skill, which includes contributions to group activities, purposeful and self-directed activity, and deliverance towards instructions and questions. Moreover, play skills are also realized to be relatively helpful in diagnosing the extent of autism. It is easier for a child to develop these characteristics through play therapy; however, it is necessary to reflect upon the outlook of autistic children in this matter (Conn, 2014; Goodley \& Runswick-Cole, 2010; Theodorou \& Nind, 2010). Therefore, it can be seen that children possess the ability to express themselves naturally play and other similar activity. Play therapy therefore provides a channel for communication between the child and the therapist due to the postulation that children make use of play materials to demonstrate their thoughts and emotions in a way that they are unable to do through speech alone (Landreth, 2012). However, despite its growing recognition among clinicians, there is a lack of acceptance from the scientific community due to the dearth of soundly supportive empirical evidence (Azerrad, 2000).

Children with ASD can derive considerable benefits from early intervention program, as these programmes mainly emphasize on enhancing the rate of recurrence, function, and forms of play that may elicit improvements in communication (Paul, 2008). Children with ASD appear to display incapability to acquire interactive or play skills due to the lack of communication skills. Interventional programmes have indicated enhanced and improved social, communicative, and language behaviours among children with ASD (Chandler et al, 2013). As such, several studies have highlighted the intervention programs as significant to improve play skills among these children (Kasari \& Chang, 2014; Flippin \& Watson, 2011; Miltenberger \& Charlop, 2014).

As discussed earlier, ASD diagnoses are based on observational and descriptive approaches, whereby the behavior of the individual is monitored for the standard symptoms of ASD. These behavioral observations greatly impact the decision of a clinician to diagnose or even overrule the results of formal screenings. This study will make use of observational analysis of the test subjects to ascertain the efficacy of play therapy among autistic individuals. Through this, the determination of play therapy as an advantageous treatment intervention for autism can be made. 
The study has observed the therapeutic approaches and their outcomes within the already established settings.

\section{Method}

The study is based on observational analysis to assess the favourable influence of play therapies among autistic children. The strategy was implemented in 2017, when researchers collaborated with a local centre for children with special needs. A specific centre was selected for this study due to their routine practice of play therapy among children with ASD. The children with a clinical diagnosis of ASD, attained from a health centre were recruited in the study. Children displaying impaired social and communicative behaviour were incorporated in this study. The children with any significant motor or sensory impairments, seizures, major physical problems, psychoactive medications, pre-natal exposure to drugs or alcohol, and history of neurologic disease were excluded. Consent for the data collection had been obtained from each parent/guidance. It was ascertained that each selected child was accompanied by an adult at the time of observation. Children continued to follow their usual pattern of attendance at the specialized centre during the study period. Selected children were engaged in regular activities for participating in the therapy sessions. Children were observed for their behaviour before the beginning of therapy and at the end of all mandatory sessions. The intervention of tabletop was incorporated to assist children with communication disorders. The approach has used a variety of scripts for the development of understanding, imagination, social skills, and exploration among the children (Phillips \& Beavan, 2012). Kits such as cars, animal sets, trains, car tracks and farmyards were used and the corresponding speech scripts were developed for playing with these kits. These scripts included making sounds, or reciting rhymes as the toys were played with. The autistic symptoms; such as, babbling and pointing, poor eye contact, excessive lining up of toys, abnormal interest, impaired ability to make friends, lack of smiling or social responsiveness, lack of social interaction and name non-responsiveness were investigated through the use of these kits and scripts. The program has been based on 25 hours programming that has been distributed among 2 months. A 30 minutes session was conducted each day. Behavioural aspects that are common indications of ASD have been recorded on the checklist based on the diagnostic criteria presented in DSM-5 (American Psychiatric Association, 2013) before and after conducting the investigation. The results were analysed using the Statistical Package of Social Sciences (SPSS).

\section{Results}

A total of 250 autistic children, within the age range of 4 to 5 years, were recruited from the centre. All the children were evaluated for the presence and absence of characteristic behavioural aspects of ASD. Later, they were assessed for the same symptoms after the completion of the therapeutic program. Similar checklist was used for both the pre and post analysis. The results indicated $100 \%$ of incidence for behavioural symptoms among autistic children before the therapy. The results for the occurrences of attitudinal features have been displayed in Table 1 .

Table 1. Pre and post analysis for the efficacy of play therapy on autistic children

\begin{tabular}{|c|c|c|c|}
\hline Autistic Symptoms & Incidence & Pre - Therapy N (\%) & Post Therapy N (\%) \\
\hline \multirow[t]{2}{*}{ Babbling and pointing } & Yes & $250(100 \%)$ & $142(56.8 \%)$ \\
\hline & No & $250(100 \%)$ & $108(43.2 \%)$ \\
\hline \multirow[t]{2}{*}{ Poor eye contact } & Yes & $250(100 \%)$ & $130(52 \%)$ \\
\hline & No & $250(100 \%)$ & $120(48 \%)$ \\
\hline \multirow[t]{2}{*}{ Excessive lining up of objects or toys } & Yes & $250(100 \%)$ & $155(62 \%)$ \\
\hline & No & $250(100 \%)$ & $95(38 \%)$ \\
\hline \multirow[t]{2}{*}{ Abnormally intense or focused interest } & Yes & $250(100 \%)$ & $129(51.6 \%)$ \\
\hline & No & $250(100 \%)$ & $121(48.4 \%)$ \\
\hline \multirow[t]{2}{*}{ Impaired ability to make friends } & Yes & $250(100 \%)$ & $127(50.8 \%)$ \\
\hline & No & $250(100 \%)$ & $123(49.2 \%)$ \\
\hline \multirow[t]{2}{*}{ No smiling or social responsiveness } & Yes & $250(100 \%)$ & $98(39.2 \%)$ \\
\hline & No & $250(100 \%)$ & $152(60.8 \%)$ \\
\hline \multirow[t]{2}{*}{ Lack of social interaction } & Yes & $250(100 \%)$ & $137(54.8 \%)$ \\
\hline & No & $250(100 \%)$ & $113(45.2 \%)$ \\
\hline \multirow[t]{2}{*}{ No response to name } & Yes & $250(100 \%)$ & $119(47.6 \%)$ \\
\hline & No & $250(100 \%)$ & $131(52.4 \%)$ \\
\hline
\end{tabular}




\section{Discussion}

This study carried out an assessment of 250 autistic children within the age range of 4-5 years. This age range was chosen on the basis of earlier conducted studies that conducted investigations on children between 3-6 years of age (Landa, 2008). Furthermore, the same study highlighted the favorable contributions of early diagnosis to the conduction of early behavior-based interventions. Such early interventions were seen to have a positive correlation with improvements in social and communicative interactions (Landa, 2008). The pre and post analysis conducted in the present study has presented alterations in the behavioural symptoms among the children with autistic spectrum disorder. Few of the previous studies have presented positive behaviours with the implementation of play therapies among children (Kasari \& Chang, 2014; Bryan \& Gast, 2000). According to Kasari and Chang (2014), the children, who underwent the play therapy did not respond to the intervention. These findings were parallel to the outcomes of present study. Lower incidence of improvement can be attributed to a diverse range of causes, among which the lack of training among parents and their lack of participation in the therapeutic sessions are the main ones. Parental involvement has been marked significant to generate individual improvements in each child (Kasari \& Chang, 2014). Conversely, the results of the present study did not express significant likelihood for the diminution of symptoms among autistic children, similar to the study conducted by Kasari and Change (2014).

Solomon, et al. (2014) indicated that cohesiveness and emotional support, provided by parents is significantly correlated with the social abilities and skills among the children. Parent-led play interventions have often been identified as the factors preceding to healthy familial and social interaction with the children, without any kind of stressful or depressing reflection. Parents have also felt more comfortable during home-based sessions. The enhanced level of parent child social interaction is correlated with the active play behaviour among children with ASD. Moreover, enhancement in the interactive attitude of children is associated with longer durations of play sessions (Ingersoll et al., 2012). A study conducted by Spector \& Charlop (2017) highlighted the significance of sibling-mediated interventions for enhancing social skills of autistic children. The results showed that majority of the children with ASD depicted increased capability to emulate and get involved in joint attention.

This study demonstrated results that depicted the inefficacy of play therapy as an intervention treatment for autistic children. Conversely, it was seen that an important role is played by the teachers in developing social interaction of an autistic child. Regardless of all the challenges, positive assistance from the teacher stimulated the positive environment for the children to increase interactions. Liber, et al. (2008) recruited three boys with autism, who were educated and trained to play activities that were merged with the sequence of play along with peer support. The results indicated significant increase in the attitude of one boy; while, other two learned more with time and in longer duration. Another study conducted by Parker \& O'Brien (2011) consulted literature from 18th century to 21 st century concerning the issues of disabilities, speech problems, learning difficulties, mental debilities, anxieties, childhood abuse, familial dysfunction, and trauma. All of these aspects were treated with play therapy among the affected children. The study outcomes expressed efficacy of play therapy; yet, none of the studies indicated improvement in autism.

The ASD children often display deficits in play skills and get involved in stereotypic behaviour; although, it is an important part of daily routine. A study stated that autistic children are likely to improve their play skills as a result of direct intervention embedded during their play therapy (Jung \& Sainato, 2013). Similar to the collateral effects, play therapy brings significant improvement in play skills of autistic children by increasing their social interactions and decreasing their inappropriate behaviours. A study conducted by Landreth et al. (2009) stated that play therapy encourages children to express themselves more openly, which enhance their cognitive development. Therefore, play therapy has been recognized as a helpful modality that should be implemented in the schools for the children in their early ages.

It is of relevance to mention some ethical considerations with regard to ASD diagnosis. Walsh et al. (2011) detailed the complexity of autism due to its biological heterogeneity. This biological heterogeneity means that autistic patients manifest a variety of symptoms, developmental complexities, and sensory issues. However, there is a dearth of awareness regarding the complexity of this disorder among general public. Furthermore, it is essential to consider that autistic individuals may show high and low functioning in different aspects and settings. Therefore, any ASD diagnosis must take into account both the unique strengths and unique weaknesses of that particular individual with regard to different situations. Additionally, it is to be noted that emphasis is generally placed on placing negative connotations around $\mathrm{ASD}$, by describing the primary attributes of autism as social or communicative impairments. However, emphasis should additionally be placed on listing the positive aspects of ASD, such as the ability of autistic individuals to develop intense focus, their unusual memory and strong attention 
to detail (Baron-Cohen, 2000).

Autistic children characteristically express power interaction; therefore, a diversified range of intervention programs are encouraged in accordance with standardized principles. The developmental approaches of autistic children tend to differ from normal children, as they require different facilities and special attention. Subsequently, researchers must focus to come up with other helpful modalities that can contribute to the behavioural adaptions of children with special needs. Interventions based on play skills are recognized as imperative approach to develop social associations among children. More studies are required to provide such treatments with scientific validity and to fulfil the gaps through investigating long-term effects of play skills on developmental, functional, communication, social, and academic approaches in children with autism.

\section{Acknowledgements}

The author is very thankful to all the associated personnel in any reference that contributed in/for the purpose of this research. Further, this research holds no conflict of interest and is not funded through any source.

\section{Competing Interests Statement}

The author declares that there are no competing or potential conflicts of interest.

\section{References}

Abrahams, B., \& Geschwind, D. (2008). Advances in autism genetics: On the threshold of a new neurobiology. Nature Reviews. Genetics, 9(5), 341-355. https://doi.org/10.1038/nrg2346

American Psychiatric Association. (2013). Diagnostic and statistical manual of mental disorders (DSM-5®). American Psychiatric Pub.

Azerrad, J. (2000). Results of play therapy. Retrieved from Cambridge Center for Behavioral Studies Web site: Retrieved from http://www. behavior. org/parenting/parenting_play_therapy. cfm.

Baron-Cohen, S. I. M. O. N. (2000). Is Asperger syndrome/high-functioning autism necessarily a disability?. Development and psychopathology, 12(3), 489-500. https://doi.org/10.1017/S0954579400003126

Bratton, S. C., Ray, D., Rhine, T., \& Jones, L. (2005). The efficacy of play therapy with children: A meta-analytic review of treatment outcomes. Professional Psychology: Research and Practice, 36(4), 376. https://doi.org/10.1037/0735-7028.36.4.376

Bryan, L. C., \& Gast, D. L. (2000). Teaching on-task and on-schedule behaviors to high-functioning children with autism via picture activity schedules. Journal of autism and developmental disorders, 30(6), 553-567. https://doi.org/10.1023/A:1005687310346

Chandler, S., Carcani-Rathwell, I., Charman, T., Pickles, A., Loucas, T., Meldrum, D., \& Baird, G. (2013). Parent-reported gastro-intestinal symptoms in children with autism spectrum disorders. Journal of autism and developmental disorders, 43(12), 2737-2747. https://doi.org/10.1007/s10803-013-1768-0

Conn, C. (2014). Investigating the social engagement of children with autism in mainstream schools for the purpose of identifying learning targets. Journal of Research in Special Educational Needs, 14(3), 153-159. https://doi.org/10.1111/1471-3802.12010

Courchesne, E., \& Pierce, K. (2005). Brain overgrowth in autism during a critical time in development: implications for frontal pyramidal neuron and interneuron development and connectivity. International journal of developmental neuroscience, 23(2-3), 153-170. https://doi.org/10.1016/j.ijdevneu.2005.01.003

Flippin, M., \& Watson, L. R. (2011). Relationships between the responsiveness of fathers and mothers and the object play skills of children with autism spectrum disorders. Journal of Early Intervention, 33(3), $220-234$. https://doi.org/10.1177/1053815111427445

Goldstein, H. (2002). Communication intervention for children with autism: A review of treatment efficacy. Journal of autism and developmental disorders, 32(5), 373-396. https://doi.org/10.1023/A:1020589821992

Goodley, D., \& Runswick - Cole, K. (2010). Emancipating play: Dis/abled children, development and deconstruction. Disability \& society, 25(4), 499-512. https://doi.org/10.1080/09687591003755914

Grether, J., Anderson, M., Croen, L., Smith, D., \& Windham, G. (2009). Risk of autism and increasing maternal and paternal age in a large north american population. American Journal of Epidemiology, 170(9), 1118-1126. https://doi.org/10.1093/aje/kwp247 
Howlin, P. (2010). Evaluating psychological treatments for children with autism-spectrum disorders. Advances in psychiatric treatment, 16(2), 133-140. https://doi.org/10.1192/apt.bp.109.006684

Jana Mertz, M. B. A. (2013). Preferred play activities of children with autism spectrum disorder in naturalistic settings. North American Journal of Medicine and Science, 6(3). https://doi.org/10.7156/najms.2013.0603128

Jung, S., \& Sainato, D. M. (2013). Teaching play skills to young children with autism. Journal of Intellectual and Developmental Disability, 38(1), 74-90. https://doi.org/10.3109/13668250.2012.732220

Kasari, C., \& Chang, Y. C. (2014). Play development in children with Autism Spectrum Disorders: Skills, object play, and interventions. Handbook of Autism and Pervasive Developmental Disorders (4th ed.). https://doi.org/10.1002/9781118911389.hautc11

Kasari, C., Freeman, S., \& Paparella, T. (2006). Joint attention and symbolic play in young children with autism: A randomized controlled intervention study. Journal of Child Psychology and Psychiatry, 47(6), 611-620. https://doi.org/10.1111/j.1469-7610.2005.01567.x

Kogan, M. D., Blumberg, S. J., Schieve, L. A., Boyle, C. A., Perrin, J. M., Ghandour, R. M., ... \& van Dyck, P. C. (2009). Prevalence of parent-reported diagnosis of autism spectrum disorder among children in the US, 2007. Pediatrics, 124(5), 1395-1403. https://doi.org/10.1542/peds.2009-1522

Landa, R. J. (2008). Diagnosis of autism spectrum disorders in the first 3 years of life. Nature Reviews Neurology, 4(3), 138. https://doi.org/10.1038/ncpneuro0731

Landreth, G. L. (2012). Play therapy: The art of the relationship. Routledge.

Landreth, L., Ray, D. E., \& Bratton, S. (2009). Play Therapy in Elementary Schools. Psychology in the Schools, 46(3), 281-289. https://doi.org/10.1002/pits.20374

Liber, D. B., Frea, W. D., \& Symon, J. B. (2008). Using time-delay to improve social play skills with peers for children with autism. Journal of Autism and Developmental Disorders, 38(2), 312-323. https://doi.org/10.1007/s10803-007-0395-z

Lillard, A. S., Lerner, M. D., Hopkins, E. J., Dore, R. A., Smith, E. D., \& Palmquist, C. M. (2013). The impact of pretend play on children's development: A review of the evidence. Psychological bulletin, 139(1), 1. https://doi.org/10.1037/a0029321

Lord, C. (2010). Social Policy Report. Autism Spectrum Disorders Diagnosis, Prevalence, and Services for Children and Families. Sharing child and youth development knowledge, 24(2), 1-27.

Miller, V. A., Schreck, K. A., Mulick, J. A., \& Butter, E. (2012). Factors related to parents' choices of treatments for their children with autism spectrum disorders. Research in Autism Spectrum Disorders, 6(1), 87-95. https://doi.org/10.1016/j.rasd.2011.03.008

Miltenberger, C. A., \& Charlop, M. H. (2014). Increasing the athletic group play of children with autism. Journal of autism and developmental disorders, 44(1), 41-54. https://doi.org/10.1007/s10803-013-1850-7

Parker, N., \& O'Brien, P. (2011). Play Therapy-Reaching the Child with Autism. International Journal of Special Education, 26(1), 80-87.

Paul, R. (2008). Interventions to improve communication in autism. Child and adolescent psychiatric clinics of North America, 17(4), 835-856. https://doi.org/10.1016/j.chc.2008.06.011

Phillips, N., \& Beavan, L. (2012). Teaching Play to Children with Autism: Practical Interventions Using Identiplay. Sage Publications. https://doi.org/10.4135/9781446251232

Piaget, J. (1962). The relation of affectivity to intelligence in the mental development of the child. Bulletin of the Menninger clinic, 26(3), 129.

Spector, V., \& Charlop, M. H. (2017). A Sibling-Mediated Intervention for Children with Autism Spectrum Disorder: Using the Natural Language Paradigm (NLP). Journal of autism and developmental disorders, 1-15. https://doi.org/10.1007/s10803-017-3404-x

Theodorou, F., \& Nind, M. (2010). Inclusion in play: a case study of a child with autism in an inclusive nursery. Journal of Research in Special Educational Needs, 10(2), 99-106. https://doi.org/10.1111/j.1471-3802.2010.01152.x 
Walsh, P., Elsabbagh, M., Bolton, P., \& Singh, I. (2011). In search of biomarkers for autism: scientific, social and ethical challenges. Nature Reviews Neuroscience, 12(10), 603. https://doi.org/10.1038/nrn3113

Wong, C. S., Kasari, C., Freeman, S., \& Paparella, T. (2007). The acquisition and generalization of joint attention and symbolic play skills in young children with autism. Research and Practice for Persons with Severe Disabilities, 32(2), 101-109. https://doi.org/10.2511/rpsd.32.2.101

\section{Copyrights}

Copyright for this article is retained by the author(s), with first publication rights granted to the journal.

This is an open-access article distributed under the terms and conditions of the Creative Commons Attribution license (http://creativecommons.org/licenses/by/4.0/). 